\title{
THE CURRENT CHALLENGES IN THE REGULATORY SYSTEM OF ACCOUNTING AND AUDITING ACTIVITIES IN GEORGIA
}

\author{
PANTELEIMON (PAATA) KLDIASHVILI \\ PhD Student, \\ Sokhumi State University, \\ Associate Professor \\ Kutaisi University, Georgia \\ paata.kldiashvili@yahoo.com
}

KEYWORDS: AUDITING, ACCOUNTING, REGULATION, SELF-REGULATION.

For citation: Kldiashvili, P. (2019). The Current Challenges In The Regulatory System Of Accounting And Auditing Activities In Georgia, Globalization And Business, №8, pp. 178-184. https://doi.org/10.35945/gb.2019.08.023

Introduction. Accounting and auditing are essentia elements of contemporary economic relations. Their importance and the need for their development are constantly growing. Such relevance of the issue has paved the way for our interest in this subject, and accordingly, the purpose, objectives, subject, methods and the informational basis of research have been determined.

The purpose of research is to identify the areas where improvements could be made in accounting and auditing regulation for private sector enterprises in Georgia, based on international experience, the country's international commitments and the characteristic features of economic development.

The object of research is the process of introduction and development of a modern system of accounting and auditing in Georgia since the 1990s until today.

The research subject is the of accounting and auditing regulation/self-regulation system existing in Georgia and its impact on the development of these fields.

Research methods. In the research process, methods of induction, deduction, comparative analysis, synthesis, statistical observation, generalization, abstraction, analogue, systemic approach, modeling and institutional analysis were used.

An informational base for research is represented by laws and regulations acting in Georgia at various times, international agreements, professional standards, as well as information placed on the webpages of Council of Auditing Activities of the Parliament of Georgia, the Service for Accounting, Reporting and Auditing Supervision of the Ministry of Finance of Georgia, National Statistics Office of Georgia, and professional organizations of of accountants and auditors.
Analysis of the experience of different countries confirms that compliance of accounting and auditing with modern requirements of economic development is conditioned by a well-organized regulatory system. The establishment of such a system is a complex and lengthy process. Georgia is not an exception in this context, where since the 1990s until today, the search continues for the directions of the improvement of accounting and auditing regulation, as well as the establishment of a legal framework oriented to sustainable development.

The process of the establishment and development of the accounting standardization and regulation system started at the international level in the 1970s, following the establishment of international professional organization of accountants Accountants International Professional Organization the International Accounting Standards Committee (IASC). Since it was founded, this organization has been actively working, on the one hand, on developing standards, and on the other hand, on ensuring that as many countries as possible in the world could use these standards, or bring their own legislations in line with these standards. The main emphasis was placed on harmonization of existing British-American and European national standards of accounting with international standards in this field. The study and analysis of these experiences allows us for asserting that the modern systems of these countries have some aspects that may be of interest for the search for ways of further development of accounting regulatory system in Georgia.

In addition to analyzing trends in the accounting regulatory system development, not less interesting (if not more) is the process of introduction and evolution of auditing in the modern world. Auditng regulation has a long history, but 
in modern form, this issue has become relevant since the 1970s. Consequently, the development of auditing standards has begun, leading to the formation of professional organizations of auditors and the auditing regulatory state agencies. In addition, these processes in different countries have been developed differently, although, owing to high expectations from the public with reagard to audit, these activities receive a great deal of attention in almost all countries, and the relevant State bodies or professional organizations are systematically trying to contribute to their continuous development and improvement. It is for this purpose that the state regulation/self-regulation of auditing activities is provided.

The high level of the public interest in auditing activities in any country makes it essential to create an environment that ensures the development of the audit profession. As a rule, the State and professional organizations, which, accordingly, perform the function of regulation and self-regulation, are jointly participating in creating such an environment. However, the role of each of them varies from country to country. In particular, in the countries of continental Europe (France, Germany) the State, through its institutions, intervenes in regulation of auditing activities, while in the United States, Great Britain and Canada, the supervision exercized by the state organs over the field of audit, until recently, has been minimized, and decade after decade, it has worked quite successfully only under self-regulation onditions. After the worldclass auditing scandals with the "Enron" and "Arthur Andersen", increasing the State's regulatory role in the field of audit became even more relevant in these countries as well. It is from this standpopint that on 17 May 2006, the European Union adopted a directive (2006/43/EC) on a mandatory audit of annual and consolidated reporting (J.: ACcounting, 2010: \#2(122)). According to this directive, Member States are obligated to set up relevant competition agencies and put under state supervision all auditors and auditing companies carrying aut the mandatory audits.

The transformation processes taking place in the world in the field of accounting and audit were relatively late reflected in Georgian reality that is associated with the radical political and economic changes that occurred in the last decade of the 20th century. As a result, it became necessary to establish a completely new accounting system different from the existing one, and simultaneously, to introduce a different form of financial control - audit. To this end, the establishment of the legislative and regulatory basis had started on the one hand, and on the other hand, their use in practice had begun. In particular, the Parliament of Georgia adopted the Law On Auditing Activities (07.02.1995) and the Law On Accounting and Reporting Regulation (05.02.1999), and the President of Georgia (through executive order) approved the Accounting and Reporting Policy Regulations in Georgia (No $70,06.02 .1998)$. The regulatory bodies provided for by the legislation have also been created. At the beginning of the 21st century, after several unsuccessful attempts to change the legislation, in 2012 a new law On Accounting and Financial Audit (29.06.2012) was adopted. However, as noted earlier, in 2016 it was replaced by the Law of Georgia On Accounting, Reporting and Auditing (08.06.2010).
The main findings of the analysis and assessment of these laws and regulations can be generalized as follows:

- At the beginning of the 21st century, from the methodological and organizational standpoints, substantial work is still needed in the country in the field of accounting and auditing, since the existing legislative and regulatory framework failed to comply adequately with modern requirements of modern, and rerquired an in-depth revision and improvement;

- Virtually no regulation or self-regulation of accounting and auditing were consistently and purposefully carried out in the private sector. No single organization had any appropriate leverage or resources to carry out of this such a highly complex and responsible function, and that is also important, the motivation for this;

- The regulatory model for the field of accounting and auditing proposed by legislation in force is flexible enough, and can be effective in case of proper implementation in practice. This does not mean that the law is ideal. Once enacted, many provisions of this law may need to be modified and improved - and some signs for this have already appeared. Although, it is a natural process and does not present particular difficulties. The substantially more complex challenge that the field of accounting and auditing is currently facing is the full de facto enactment of the de jure existing law, which is quite difficult and arduous, but not a compelling task. To this end, first, it is necessary to create the full-fledged mechanisms for practical implementation of the provisions of this law - timely adoption of required sub-legislative regulatory provisions and the effective functioning of the service and council, as well as professional organizations established based on the law; the commitment of country's government and international donor organizations, and most importantly - the maximum activity of representatives of this profession themselves, as well as their greater involvement in the processes;

- The main advantage of a new law is that the proposed model of developing the field of accounting and auditing is realistic and practically applicable, unlike its predecessors, whose ineffectiveness and nonviability were clearly seen both in the approval process and during its use in practice.

The analysis of the legislative frameworks in force, established practice and international experience allows us for defining the major aspects of the regulatory improvement of accounting and auditing activities, as well as for developing measures that must be undertaken in the separate important areas. In particular:

- To determine an optimal model of accounting. In the light of current situation existing in Georgia in the field of accounting, we believe that in planning the development of accounting, it would be better to focus on a continental model (German-French synthesis), since those two major factors (the focus of the business sector on a big banking capital and compliance with fiscal policies), on which this model is built, plays an important role in our country's reality as well;

- To identify the levels of accounting records maintenance. International practice had clearly demonstrated that accounting records maintenance in the economic entities of 
different sizes with the same standards and equal quality, should be considered unreasonable. Accordingly, we consider appropriate the regulation established by Law of Georgia On Accounting, Reporting and Auditing with regard to defining four categories of enterprises, with the following clarifications: within the fourth category of enterprises, to separate the relatively small-size entities, which will meet at least two of the following three criteria:

a) The total value of assets does not exceed GEL 50 thousand;

b) An annual income does not exceed GEL 100 thousand;

c) The average annual number of employees in the reporting period does not exceed 5 .

They should not be required to keep records on the principle of double entry accounting. They should have the opportunity to use a single-entry account method, by means of which they will be able to record income and expenditure in chronological order, as well as to determine the financial result (profit or loss) of the activities.

- More effective use of resources of the International Federation of Accountants (IFA) and other international organizations at the national level. The analysis revealed that the main determinant of our national accounting and auditing practice's lagging behind the modern European level is, on the one hand, the better starting positions, which naturally had the European countries, and on the other hand, the variety of projects, which, unlike us, they continuously implemented for development in this field. Accordingly, order to remove the existing backwardness, it is necessary to deepen integration with IFA and other international organizations, as well as to make maximum use of their resources. In this regard, the measures recently undertaken by the Service for Accounting, Reporting and Auditing Supervision are commendable, which implies preparing and publishing various instructions, recommendation guidelines, self-study books and other support materials;

- Accelerating research on developing the accounting and auditing field. For the development of the field of accounting and auditing, we deem it would be advisable for representatives of this profession (scholars and practitioners) to set up standing and interim (as needed) working groups, which will examine a variety of specific issues in this field, and will develop specific guidelines, recommendations and definitions of professional practitioners. It is welcome that in accordance with Article 20 of Law of Georgia On Accounting, Reporting and Auditing: "The Service, for the purpose of developing standards and rules set out under this Law, shall be entitled to establish working groups with the participation of professional organizations, practitioners and other stakeholders". It is these groups that may work on issues such as, for example, improving the quality of financial accounting, bringing tax accounting closer to financial accounting, improving the managerial accounting methodology in accordance with country-specific circumstances and so on;

- Setting up effective regulatory and/or self-regulatory body of the field of accounting and auditing. In accordance with Law of Georgia On Accounting, Reporting and Auditing, the creation of the State's supervision body - the Service for
Accounting, Reporting and Auditing Supervision (SARAS) and the Council of Accounting, Reporting and Auditing within the Ministry of Finance of Georgia, is undoubtedly to be regarded as a step forward, however, we deem it advisable to establish them as a fully independent system;

- Establishing the auditing quality control system. Since the introduction of auditing activities until today, the quality control of this services has never been really carried out to varying degrees in Georgia. In this regard, there is a need for the practical implementation of the quality control mechanisms, as well as ensuring continuous monitoring of this process, with a view to improve it operatively, when necessary. In addition, the quality control system should not be only oriented to punishment, but also it should be aimed at preventing the unsatisfactory-quality services assisting to service providers. This is why we believe that it would be appropriate, at the first stage, to adopt the practice of the voluntary control of the quality of auditing firms, in the framework of which, in the case of shortcomings observed as result of the verification, auditing firms will not be sanctioned, but they will be provided with specific recommendations on their elimination within a certain reasonable period.

- Ensuring compliance with international standard requirements for financial accounting. When creating the relevant mechanisms, if necessary, the appropriate enforcement tools, including various sanctions, should be taken into consideration, although at the initial stage, we do not consider it appropriate to impose strict sanctions on those who are not able to remain fully in compliance with the requirements of the relevant standards/rules. The Supervisory Authority must act on the basis of one of the findings of research ${ }^{1}$ conducted by the World Bank Group in 2007 in Georgia: "The quality of compliance with standards when maintaining financial records in the economic entities is low, not because someone does not want to observe them, but because of low awareness of these requirements". Consequently, the regulator's action should not be aimed primarily at punishing and sanctioning, but at assisting and supporting, as well as at improving opportunities and training;

- Introduction of the continuous education system. The importance of the continuous education system is beyond questions, which is also confirmed by attention paid to this issue by IFA and its member states. We believe that in order to develop the accounting and auditing field in Georgia, based on the existing situation of the country, it is doubly important to take care of updating knowledge of representatives of this profession. Particular attention should be given to this issue in the regions, where people have significantly less access to professional novelties and the refresher courses, than in the capital. Annual trainings within the continuing education system should become a mandatory requirement for auditors; and as for accountants, profesional organizations should offer them such an interesting and useful program that they are willing to cooperate with them, without being compelled to do so;

- Improvement of the regulatory legal framework.

${ }^{1}$ Research on the observance standards and codes in accounting and auditing (ROSC), 2007, p. 24. 
Although the existing law is the most optimal as compared to its all other predecessors, its further improvement should be a continuing concern. In addition, in the process of the creation and revising the legislation and by-laws, we should take into account, on the one hand, the commitments made under the Association Agreement with the European Union, and on the other hand, all this Agreement is offering.

Conclusion. Studies conducted allow us for compiling the regulating algorithm consisting of three main components: training and certification; methodical and methodological support; and supervision.

Training and certification. Training (including continuous training), in compliance with programms accredited by the Servce, should be provided by professional organizations; certification should be independently provided by the National Assessment and Examination Center on the basis of passing the professional examination, in compliance with the examination program accredited by the Service.

Methodical and methodological support. Studies conducted clearly demonstrate a low level of compliance with professional standard requirements and practice in Georgia that is mostly due to the lack of appropriate methodologies, methodical guidelines, supporting manuals and legal acts. A high level of this correlation has also been confirmed using the examples of many other countries. In the component, we should highlight the preparation of these materials on the one hand, and on the other hand, transfering them directly to the consumer. We believe that the preparation of materials should be provided by the Service for Accounting, Reporting and Auditing Supervision in close cooperation with international and local professional organizations and academic staff; these materials should be transferred to representatives of the profession/practioners by professional organizations. It may be stated unequivocally that activities carried out in this area in the country for decades were insufficient, and the first steps taken in the country in recent years after the establishment of the Service for Accounting, Reporting and Auditing Supervision within the Ministry of Finance, are evident.

Supervision. This is a key component of the algorithm, which should ensure the effective functioning of the remaining components. It should become a guarantor of compliance with the requirements of national legislation, international standards and other regulating documents and the minimum requirements of the quality of services provided. Based on the conducted studies, it may be stated unequivocally that the only optimal option in modern conditions for our country is the existence of a state supervisory body in the field of accounting and auditing. Furthermore, for this stage, the functioning of the Service for Accounting, Reporting and Auditing Supervision within the Ministry of Finance is not a bad decision, although in order to increase the effectiveness of activities, it is necessary to implement gradual transformation of the Service in accordance with the model we have proposed (see a scheme).
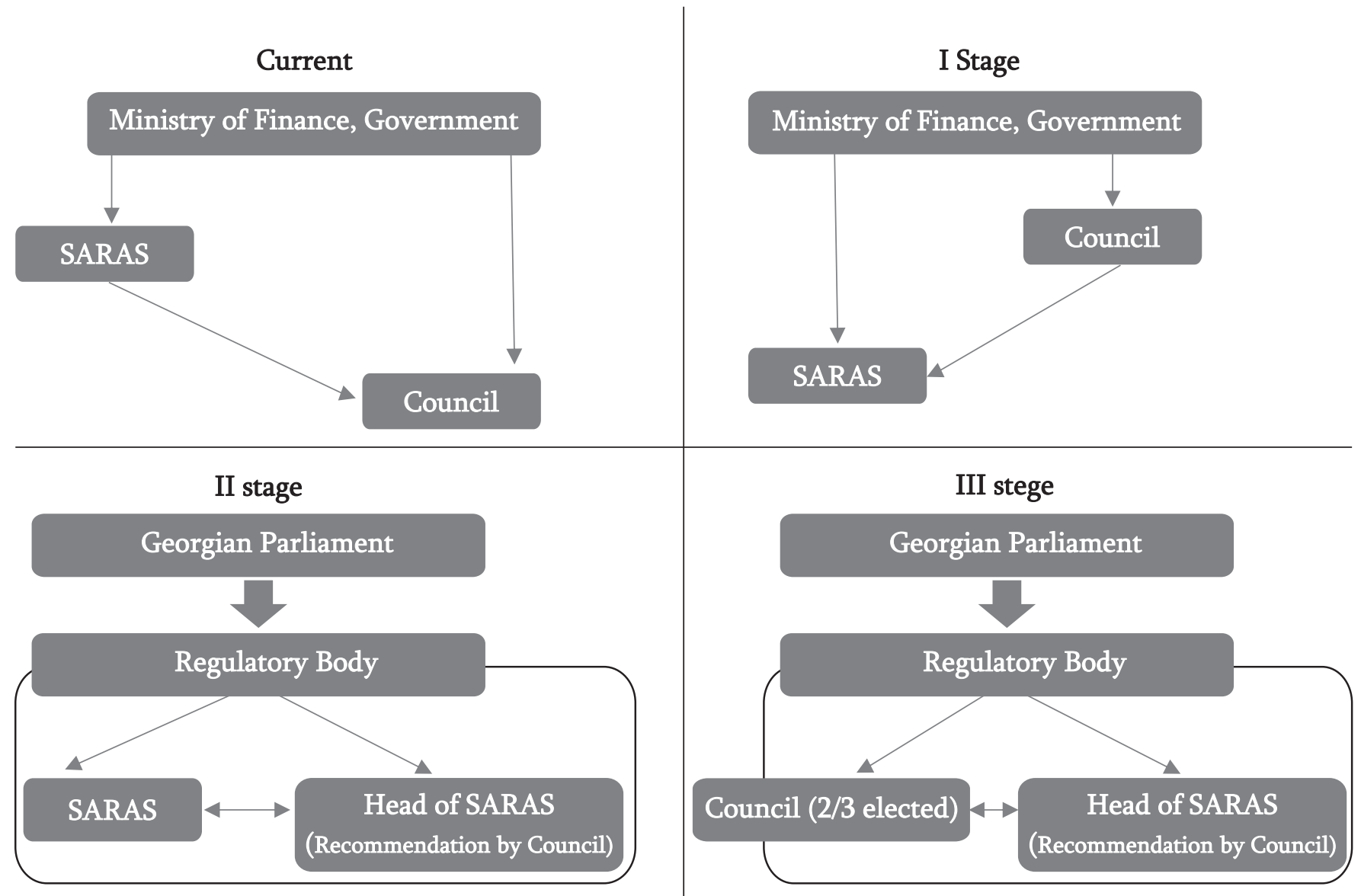

Scheme: gradual transformation model 


\section{Current situation:}

- The Service is the State institution within the Ministry of Finance of Georgia, which is organizationally positioned under the Government and the Minister of Finance. The head of the Service is appointed by the Prime Minister in consultation with the Minister of Finance of Georgia;

- The Council is the organ for reviewing the issues related to accounting, reporting and auditing and making relevant decisions, whose members are approved by the Prime Minister in consultation with the Minister of Finance of Georgia.

The $\mathbf{1}^{\text {st }}$ stage of transformation (the next $\mathbf{3}$ years):

- The degree of independence of the Service from the Ministry of Finance and the Government is increasing;

- The functions and the role of the Council are increasing. It takes on approximately the same responsibilities as the representative body of State power and the supervisory council in the business;

- The candidate for the head of the Council is chosen in consultation with the Council (and not only through consultation).
The $2^{\text {nd }}$ stage of transformation (the next $\mathbf{5}$ years):

- The Service passes from the control of the Government to the control of the Parliament;

- The Council members are elected by the Parliament, in consultation with the relevant services, including professional organizations;

- The head of the Service is approved by the Parliament, in cosultation with the Council;

- The Service is funded according to a specific rule of financing, which cannot be associated with the amounts of funds recovered on the basis of found financial irregularities.

\section{The $3^{\text {rd }}$ stage of transformation (the next 5 years):}

- Certified accountants and auditors registered in the Registry Service are involved in the election of Council members. In particular, initially half of the members of the Council, and then two thirds are elected by certified accountants and auditors by secret ballot. The elected candidates will be approved by the Parliament.

The expected timeframe for each stage of transormation has been determined based on the current realities, and it may change in accordance with the developments.

\section{REFERENCES:}

1. Alagardova G. .... (2015). Report on the Observance of Standards and Codes, Accounting and Auditing - Georgia. World Bank.

2. Gilen F. ... (2007). Report on the Observance of Standards and Codes, Accounting and Auditing - Georgia. World Bank.

3. Accounting and Reporting Policy Regulations in Georgia, approved the President of Georgia (through executive order, No 70, 06.02.1998)

4. Directive 2006/43/EC of the European Parliament and of the Council on statutory audits of annual accounts and consolidated accounts. (2006), Official Journal of the European Union, p.:87-107.

5. Georgian Law On Accounting and Reporting Regulation. Georgian Parliament, Tb., 05.02.1999.

6. Georgian Law On Auditing Activities. Georgian Parliament, Tb., 07.02.1995.

7. Georgian Law On Accounting and Financial Audit Regulation. Georgian Parliament, Tb., 29.06.2012.

8. Georgian Law On Accounting, Reporting and Audit Regulation. Georgian Parliament, Tb., 08.06.2016.

9. Official webpage of Service for Accounting, Reporting and Auditing Supervision (SARAS), (2019): www.saras.gov.ge

10. Official webpage of the Federation of Auditors, Accountants and Financial Managers, (2019): www.gfaafm.ge

11. Official webpage of the Federation of Professional Accountants and Auditors, (2019): www.gfpaa.ge

12. Official webpage of the Legislative Heralds of Georgia, (2019): www.matsne.gov.ge 


\title{
THE CURRENT CHALLENGES IN THE REGULATORY SYSTEM OF ACCOUNTING AND AUDITING ACTIVITIES IN GEORGIA
}

\author{
PANTELEIMON (PAATA) KLDIASHVILI \\ PhD Student, \\ Sokhumi State University, \\ Associate Professor \\ Kutaisi University, Georgia \\ paata.kldiashvili@yahoo.com
}

KEYWORDS: AUDITING, ACCOUNTING, REGULATION, SELF-REGULATION.

For citation: Kldiashvili, P. (2019). The Current Challenges In The Regulatory System Of Accounting And Auditing Activities In Georgia, Globalization And Business, №8, pp. 178-184. https://doi.org/10.35945/gb.2019.08.023

\section{SUMMARY}

Accounting and auditing are essential elements of contemporary economic relations. Their importance and the need for their development are constantly growing. Such relevance of the issue has paved the way for our interest in this subject, and accordingly, the purpose, objectives, subject, methods and the informational basis of research have been determined.

The purpose of research is to identify the areas where improvements could be made in accounting and auditing regulation for private sector enterprises in Georgia, based on international experience, the country's international commitments and the characteristic features of economic development.

The analysis of the legislative frameworks in force, established practice and international experience allows us for defining the major aspects of the regulatory improvement of accounting and auditing activities, as well as for developing measures that must be undertaken in the separate important areas. In particular:

- To determine an optimal model of accounting;

- To identify of levels of accounting records maintenance;

- More effective use of resources of the Internationa Federation of Accountants (IFA) and other international organizations at the national level;

- Accelerating research on developing the accounting and auditing field;

- Setting up effective regulatory and/or self-regulatory body of the field of accounting and auditing;

- Establishing the auditing quality control system;
- Ensuring compliance with international standard requirements for financial accounting.

- Introduction of the continuous education system;

- Improvement of the regulatory legal framework.

Conclusion. Studies conducted allow us for compiling the regulating algorithm consisting of three main components: training and certification; methodical and methodological support; and supervision.

Training and certification. Training (including continuous training), in compliance with programms accredited by the Servce, should be provided by professional organizations; certification should be independently provided by the National Assessment and Examination Center on the basis of passing the professional examination, in compliance with the examination program accredited by the Service.

Methodical and methodological support. Studies conducted clearly demonstrate a low level of compliance with professional standard requirements and practice in Georgia that is mostly due to the lack of appropriate methodologies, methodical guidelines, supporting manuals and legal acts. A high level of this correlation has also been confirmed using the examples of many other countries. In the component, we should highlight the preparation of these materials on the one hand, and on the other hand, transfering them directly to the consumer. We believe that the preparation of materials should be provided by the Service for Accounting, Reporting and Auditing Supervision in close cooperation with international and local professional organizations and academic staff; these materials should be transferred to representatives of the profession/practioners by professional organizations.

Supervision. This is a key component of the algorithm, which should ensure the effective functioning of the remain- 
ing components. It should become a guarantor of compliance with the requirements of national legislation, international standards and other regulating documents and the minimum requirements of the quality of services provided. Based on the conducted studies, it may be stated unequivocally that the only optimal option in modern conditions for our country is the existence of a state supervisory body in the field of accounting and auditing. Furthermore, for this stage, the functioning of the Service for Accounting, Reporting and Auditing Supervision within the Ministry of Finance is not a bad decision, although in order to increase the effectiveness of activities, it is necessary to implement gradual transformation of the Service in accordance with the model we have propose. 